\title{
In cervical arthroplasty, only prosthesis with flexible biomechanical properties should be used for achieving a near-physiological motion pattern
}

Manfred Muhlbauer ${ }^{1 *}$ (D, Ernst Tomasch², Wolfgang Sinz ${ }^{2}$, Siegfried Trattnig ${ }^{3}$ and Hermann Steffan ${ }^{2}$

\begin{abstract}
Background: In cervical arthroplasty, qualitative motion analysis generally investigates the position of the center of rotation (COR) before and after surgery. But is the pre-op COR suitable as reference? We believe that only a comparison against healthy individuals can answer whether a physiological motion pattern has been achieved. The aim of our study was to examine how the COR for flexion/extension after insertion of 3 biomechanically completely different types of disc prostheses compares to healthy volunteers, and whether and how prosthesis design contributes to a more natural or maybe even worse motion pattern.

Methods: In 15 healthy volunteers, MRI in flexion and in extension was taken, and the coordinates for the CORs (CORHV) from C3 to C7 were determined. Then pre- and post-op flexion/extension x-rays from 30 patients with a one-level disc prosthesis underwent analysis for determination of COR from C3 to C7; 10 patients who received a Bryan, a Prestige STLP, or a Discover prosthesis were chosen, respectively. Change of post-op COR position was investigated in relation to the COR-HV.

Results: The pre-operative COR is not congruent with the COR found in healthy subjects and therefore cannot be used as reference for investigation whether a disc prosthesis resembles natural motion. However, the comparison with healthy individuals shows that prosthesis insertion can change the coordinates of the COR to any direction in all levels from C3/4 to C6/7 regardless of the operated segment. Prostheses with flexible biomechanical properties can contribute to shift the COR toward normal, but devices with unphysiological biomechanical design, like fixed ball socket designs, for instance, can make the motion pattern even worse.

Conclusions: Even if the small cohorts in our study do not allow strong conclusions, it seems that in cervical arthroplasty, the biomechanical concept of the prosthesis has a significant impact whether a near-physiological motion pattern can be achieved or not. As it is a rumor but not scientifically proven that prosthesis design has no influence on clinical outcome, surgeons should only choose devices with flexible biomechanical properties for disc replacement.
\end{abstract}

Keywords: Cervical spine biomechanics, Cervical arthroplasty, In vivo kinematic study

\footnotetext{
* Correspondence: manfred.muehlbauer@wienkav.at

${ }^{1}$ Neurosurgical Department, Donauspital SMZ-Ost, Langobardenstrasse 122,

1220 Vienna, Austria

Full list of author information is available at the end of the article
}

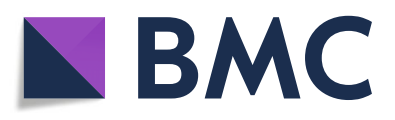

(0) The Author(s). 2020, corrected publication 2020. Open Access This article is licensed under a Creative Commons Attribution 4.0 International License, which permits use, sharing, adaptation, distribution and reproduction in any medium or format, as long as you give appropriate credit to the original author(s) and the source, provide a link to the Creative Commons licence, and indicate if changes were made. The images or other third party material in this article are included in the article's Creative Commons licence, unless indicated otherwise in a credit line to the material. If material is not included in the article's Creative Commons licence and your intended use is not permitted by statutory regulation or exceeds the permitted use, you will need to obtain permission directly from the copyright holder. To view a copy of this licence, visit http://creativecommons.org/ licenses/by/4.0/. The Creative Commons Public Domain Dedication waiver (http://creativecommons.org/publicdomain/zero/1. 0/) applies to the data made available in this article, unless otherwise stated in a credit line to the data. 


\section{Background}

Cervical disc prostheses are used to preserve motion after discectomy. But is quantitative motion preservation enough, and is it really unimportant which biomechanical concept they have? The market offers so many different devices, some with a ball socket design but with totally different radii, devices with their COR below or the COR above the respective motion segment, some with modified ball socket design that allows translation, again with their COR below or above the prosthesis, devices with 2 articulating surfaces, and finally devices with no articulating surfaces at all but motion through an elastic nucleus.

It is widely believed that the biomechanical concept has no impact on clinical outcome; however, this is hard to imagine considering the completely different motion patterns of these devices. And in fact, this is rumor and was never verified with a randomized study directly comparing different devices with respect to clinical outcome. Therefore, we believe a cervical disc prosthesis should resemble physiological motion as close as possible, and biomechanical studies on qualitative motion are still important. A variety of studies already investigated what can happen with the COR after insertion of a prosthesis, but they all use the pre-op COR as reference [1-8]. We believe that in patients with disc herniations, the COR of the affected segment is not at a physiological position anymore; therefore, investigation of qualitative motion of a disc prosthesis must compare the post-op COR against healthy volunteers rather than with the pre-op COR. This was the aim of our study, to compare pre- and post-OP COR for maximum flexion/extension from 30 patients with 3 different types of disc prostheses with 15 healthy volunteers in whom the COR was determined from flexion/extension MRI.

\section{Materials and methods Healthy volunteers}

Fifteen healthy volunteers (6 males, 9 females; age 25-53 years; mean age 37.5 years) with no previous symptoms of cervical spondylosis underwent MRI-investigation of their cervical spines after giving informed consent to the study protocol which was approved by the Ethic commission of the Medical University of Vienna (EK Nr. 571/2007).

All investigations were done using a 1.5T MRI (Siemens Avanto 1.5T; Siemens Erlangen, Germany).

The volunteers were placed in supine position and were asked to actively move their heads into maximum flexion and extension and were then supported with cushions to remain in the respective position during MRI data acquisition. T2-weighted median-sagittal slices showing the entire contours of the vertebral bodies C3 to $\mathrm{C} 7$ were used for biomechanical calculation of the respective CORs. Only datasets with no degenerative disc disease or similar degenerative changes were used for calculation.

\section{Prostheses}

We selected 3 prosthesestypes with a considerably different biomechanical concept: one with a ball socket design and its COR below (Discover; DePuy Spine, Raynham, MA, USA); one with an inverse ball socket design allowing longitudinal translation and its COR above (Prestige

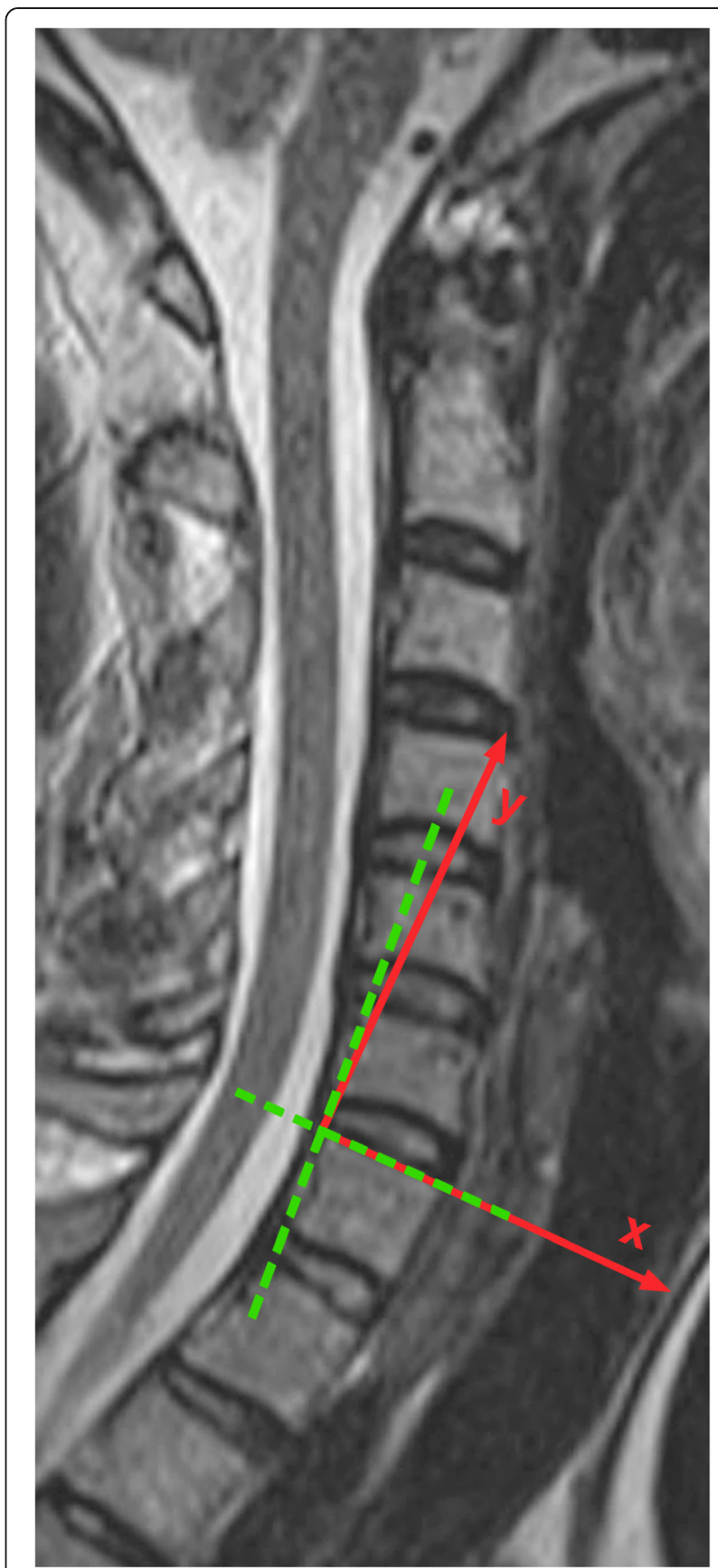

Fig. 1 Definition of the coordinate system 


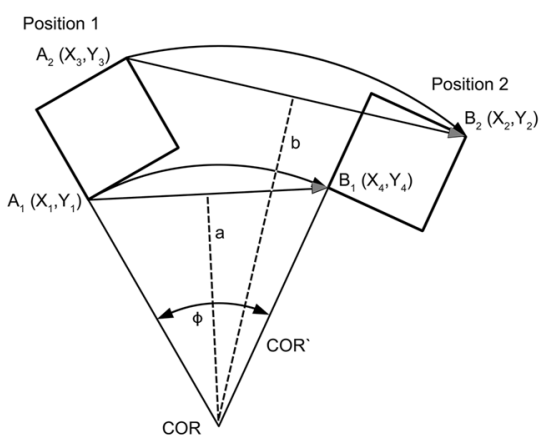

a

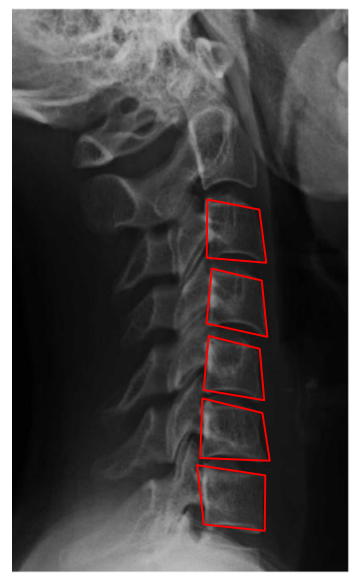

C

$$
\begin{aligned}
& C_{X}= \frac{\left(Y_{4}-Y_{2}\right) \times E-\left(Y_{3}-Y_{1}\right) \times F}{2 \times G} \\
& C O R_{Y}= \frac{\left(X_{3}-X_{1}\right) \times F-\left(X_{4}-X_{2}\right) \times E}{2 \times G} \\
& \text { for: } \quad E=X_{3}^{2}-X_{1}^{2}+Y_{3}^{2}-Y_{1}^{2} \\
& F=X_{4}^{2}-X_{2}^{2}+Y_{4}^{2}-Y_{2}^{2} \\
& G=\left(X_{3}-X_{1}\right) \times\left(Y_{4}-Y_{2}\right)-\left(X_{4}-X_{2}\right) \times\left(Y_{3}-Y_{1}\right) \\
& \varphi=\arcsin \frac{\left(X_{1}-X_{C O R}\right) \times\left(Y_{3}-Y_{C O R}\right)-\left(X_{3}-X_{C O R}\right) \times\left(Y_{1}-Y_{C O R}\right)}{\left(X_{1}-X_{C O R}\right)^{2}+\left(Y_{1}-Y_{C O R}\right)^{2}}
\end{aligned}
$$

b
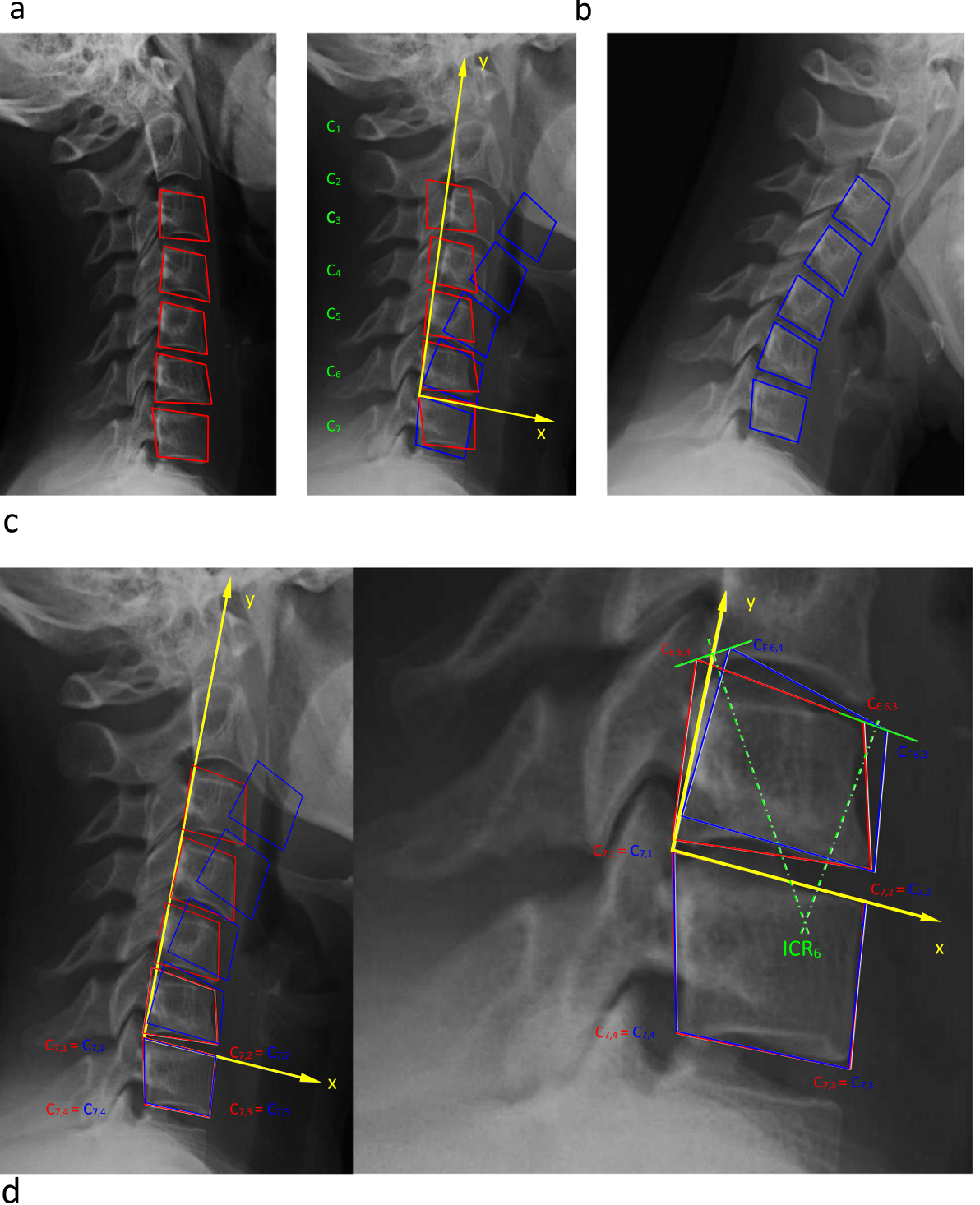

Fig. 2 Determination of the COR. a Graphically illustrates the determination of the COR. b The respective mathematical algorithm. c An example how the vertebral bodies in lateral flexion/extension $x$-rays are covered with quadrangles, the respective quadrangles of the lower vertebral body are matched, and the quadrangles of the next cranial vertebral body allow graphical or mathematical determination of the COR. $\mathbf{d}$ An example how the COR C6/7 can be determined using this technique

STLP; Medtronic, Minneapolis, MN, USA); and one with 2 articulating surfaces and a flexible COR (Bryan; Medtronic, Minneapolis, MN, USA).

\section{Patients}

Thirty patients (20 females, 10 males, age $34-59$ years, mean 45 years) who received a cervical disc prosthesis in 
Table 1 ROM C3-C7 pre- and post-op for all operated patients and for the respective subgroups Bryan, Discover, and Prestige Prosthesis and ROM in healthy volunteers HV

\begin{tabular}{|c|c|c|c|c|c|c|c|c|c|}
\hline \multirow{2}{*}{$\begin{array}{l}\mathrm{ROM}^{\circ} \\
\text { (SD) }\end{array}$} & \multirow[t]{2}{*}{$\mathrm{HV}$} & \multicolumn{2}{|l|}{ All patients } & \multicolumn{2}{|l|}{ Bryan } & \multicolumn{2}{|l|}{ Prestige } & \multicolumn{2}{|l|}{ Discover } \\
\hline & & Pre-op & Post-op & Pre-op & Post-op & Pre-op & Post-op & Pre-op & Post-op \\
\hline $\mathrm{C} 3 / 4$ & $11.4(3.4)$ & $8.5(3.7)$ & $11.3(3.9)$ & $8.7(4.0)$ & $10.6(3.7)$ & $8.6(2.9)$ & $11.9(3.2)$ & $8.2(4.6)$ & $11.4(5.0)$ \\
\hline$C 4 / 5$ & $14.9(4.8)$ & $11.9(4.7)$ & $13.5(4.3)$ & $12.5(5.5)$ & $14.9(3.8)$ & $13.2(3.7)$ & $12.6(3.2)$ & $10.0(4.5)$ & $12.8(5.5)$ \\
\hline C5/6 & $12.7(3.4)$ & $10.1(4.7)$ & $11.6(5.4)$ & $10.4(6.3)$ & $11.3(5.0)$ & $9.9(4.3)$ & $12.4(7.5)$ & $9.9(3.8)$ & $11.2(3.9)$ \\
\hline $\mathrm{C} 6 / 7$ & $14.4(5.8)$ & $7.6(4.1)$ & $7.4(4.1)$ & $8.0(4.7)$ & $7.6(4.5)$ & $7.5(4.9)$ & $7.3(5.0)$ & $7.5(2.5)$ & $7.1(3.1)$ \\
\hline $\mathrm{C3}-\mathrm{C} 7$ & $53.3(12.7)$ & $38.3(11.7)$ & $43.4(8.9)$ & 39.5 (15.3) & $44.4(9.1)$ & $37.7(8.2)$ & $43.9(6.8)$ & $37.6(11.1)$ & $41.5(11.0$ \\
\hline
\end{tabular}

one level were included in the study, 10 patients who received a Bryan prosthesis, 8 of them at C5/6 and 2 of them at $\mathrm{C6} / 7 ; 10$ patients who received a Discover prosthesis, 1 of them at C4/5, 6 at C5/6 and 3 at C6/7; and 10 patients who received a Prestige STLP prosthesis, 6 of them at C5/6 and 4 at C6/7. Twenty-six patients were operated at the author's institution and 4 patients were operated elsewhere; all of them for the generally accepted indications for arthroplasty. Surgery was performed through a standard anterior approach with micro-discectomy using the operating microscope. Correct implant position was verified intra-operatively with fluoroscopy.

The routinely taken pre- and post-operative cervical flexion/extension $\mathrm{x}$-rays were collected from their files for biomechanical analysis. If the necessary landmarks for biomechanical calculation could not be determined at $\mathrm{C6} / 7$ because $\mathrm{C} 7$ was covered from the patients' shoulders, data for $\mathrm{C} 6 / 7$ was spared from the respective dataset. Also, data was spared from further analysis when segmental ROM was below $2^{\circ}$ and therefore reliable calculation of the COR was not possible.

\section{Coordinate system}

The coordinate-system for motion analysis of flexion/extension was determined using a line through the most superior anterior and the most superior posterior point of the respective vertebral body. The cutting point with a second line through the most posterior inferior and the most posterior superior point of the respective vertebral body was defined as the center of the coordinate system with the $x$-axis passing through the most superior anterior point of the respective vertebral body, the $y$ axis directing cranially rectangular to the $x$-axis, and the $z$-axis rising orthogonally against the viewer (Fig. 1). MRI slices were obtained in $3 \mathrm{~mm}$ thickness with the same study protocol used for diagnostic MR-imaging of the cervical spine.

\section{Motion analysis}

The COR-or also described as instant center of rotation ICR in several studies-is commonly used for qualitative motion analysis and can describe how adjacent vertebral bodies move against each other [9]. Figure 2 illustrates the determination of the COR and shows an example how this was done with functional $x$-rays, for instance. Both the MRI pictures and the functional $x$ rays were manually digitized using AutoCAD ${ }^{\circ}$ software (AutoCAD ${ }^{\circ}$, AUTODESK, San Rafael, CA, USA). The vertebral bodies were covered with a quadrangle to allow better overlay of the respective vertebral bodies and to use all four edge-points of the quadrangle for a more precise calculation of the COR. Coordinate calculation was done using Microsoft Excel ${ }^{\circ}$ software (Microsoft Excel $^{\circ}$, Microsoft, Redmont, WA, USA)

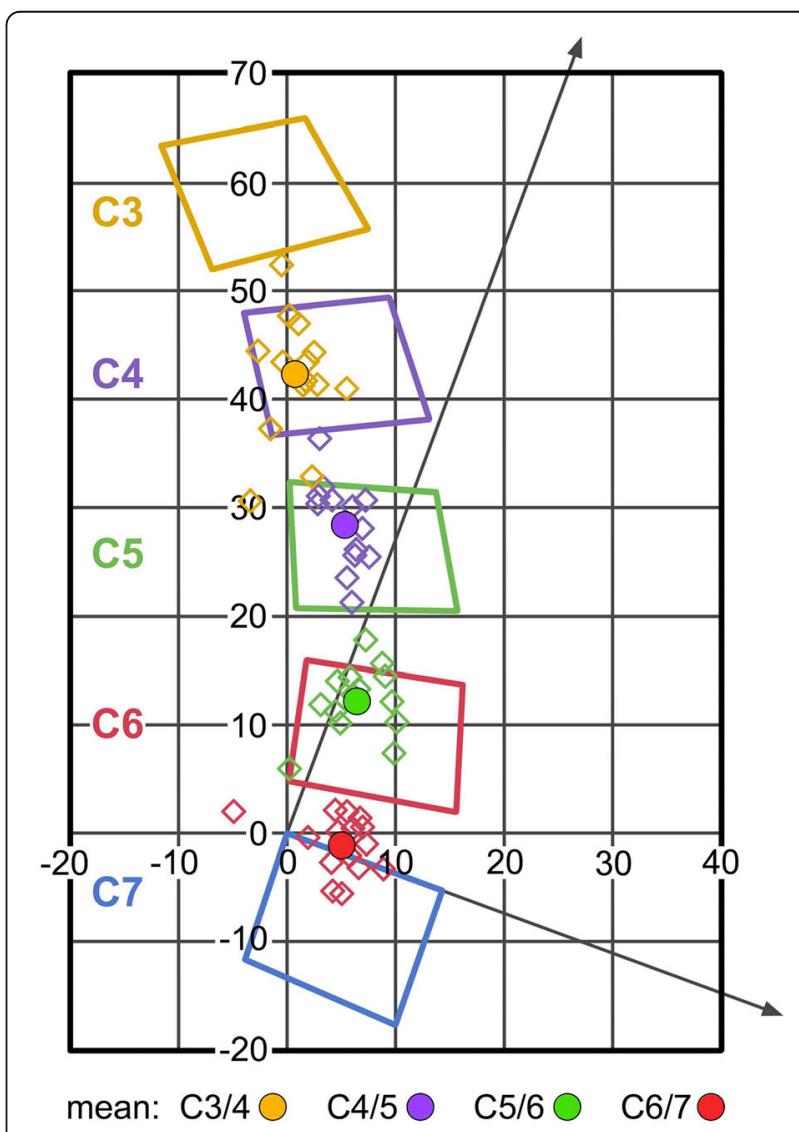

Fig. 3 Position of COR for maximum flexion/extension in healthy volunteers 
COR

COR for flexion/extension was calculated for all healthy volunteers and all patients from $\mathrm{C} 3 / 4$ to $\mathrm{C} 6 / 7$ (if possible), and separately for the 3 respective prostheses subgroups; pre- and post-op CORs were compared with the coordinates found in healthy volunteers; thus, it was determined whether the COR changed its position toward or away from the COR-HV after insertion of the 3 different types of disc prostheses.

\section{Statistical analysis}

The $t$ test was used for determination of significance regarding the differences between the respective data-sets with a significance level of $\alpha=0.05$.

Table 2 COR pre- and post-op: all patients and all levels

\begin{tabular}{|c|c|c|c|c|c|c|c|c|c|c|c|c|c|c|c|c|c|}
\hline & \multirow[t]{3}{*}{ Level } & \multicolumn{4}{|c|}{ C6/C7 } & \multicolumn{4}{|c|}{ C5/C6 } & \multicolumn{4}{|c|}{ C4/C5 } & \multicolumn{4}{|c|}{$\mathrm{C} 3 / \mathrm{C} 4$} \\
\hline & & \multicolumn{2}{|l|}{$x$} & \multicolumn{2}{|l|}{$y$} & \multicolumn{2}{|l|}{$x$} & \multicolumn{2}{|l|}{$y$} & \multicolumn{2}{|l|}{$x$} & \multicolumn{2}{|l|}{$y$} & \multicolumn{2}{|l|}{$x$} & \multicolumn{2}{|l|}{$y$} \\
\hline & & Pre & Post & Pre & Post & Pre & Post & Pre & Post & Pre & Post & Pre & Post & Pre & Post & Pre & Post \\
\hline Bryan01 & $\mathrm{C} 6 / \mathrm{C7}$ & 6.1 & 17.4 & -2 & -4.5 & 5.9 & 4.6 & -6 & -6.5 & 3.8 & 9.6 & -6.7 & -7.8 & 7.3 & 9.3 & -6.2 & -10.7 \\
\hline Bryan02 & C5/C6 & 10.8 & 5.6 & -3.2 & -0.8 & 9.8 & 12.3 & -8.1 & -8.7 & 3.9 & 8.4 & -7.7 & -5.1 & 8.8 & 6.3 & -5 & -9.3 \\
\hline Bryan03 & C5/C6 & 3.3 & 1.6 & -8.9 & -6.7 & 6.6 & 9.6 & -9.7 & -10.6 & 3 & 4.7 & -7.7 & -7.9 & 4.3 & 9.5 & -7 & -9.4 \\
\hline Bryan04 & C5/C6 & 8.3 & 11.1 & 2.1 & 3.6 & 6.1 & 8.2 & -17 & -5.5 & 10.7 & 4.1 & 4.7 & -9.2 & 10.8 & 3.5 & 12 & -8.7 \\
\hline Bryan05 & C6/C7 & 14.9 & 6.5 & -3.5 & -9.2 & & 7.7 & & -6.7 & 6.9 & 5.2 & -23.5 & -11.7 & 27.2 & 5.7 & -14.2 & -12.3 \\
\hline Bryan06 & C5/C6 & 7.9 & -5.1 & 0.2 & -0.1 & 7.3 & 7.8 & -12.3 & -12.3 & 7.9 & 7.5 & -7.2 & -7.2 & 8.8 & 7.3 & -15.6 & -12.1 \\
\hline Bryan07 & C5/C6 & 3.7 & -2.1 & -12.1 & 1 & 8.1 & 9.2 & -5.1 & -3.8 & 8.8 & 8.9 & -6.5 & -10.9 & 10.6 & 12.7 & -10.9 & -10.9 \\
\hline Bryan08 & C5/C6 & 10.7 & & -35.7 & & -8.4 & & -2.4 & & 4.3 & -0.5 & -5.4 & -11 & 11.5 & 6.1 & -5.7 & -13.8 \\
\hline Bryan09 & C5/C6 & 4.9 & 4.1 & -4 & -0.7 & 8.7 & 14.5 & -6.8 & 8.5 & 10.9 & 8.2 & -7.5 & -7.3 & 8.2 & 10.4 & -4.3 & -5.9 \\
\hline Bryan 10 & C5/C6 & 6.6 & 12.5 & 4.2 & 2 & 2 & 2.5 & -5.6 & -5.2 & 3.2 & 8.7 & -0.6 & -0.8 & 1.7 & 2.8 & -16 & 23.3 \\
\hline Discover01 & $\mathrm{C} 6 / \mathrm{C7}$ & 5.9 & 8.6 & 0.1 & -1.4 & 6.1 & 7.1 & -5.7 & -1.2 & 2.5 & 7.4 & -8.2 & -1.7 & 7.7 & 6.6 & -4.1 & 2.8 \\
\hline Discover02 & C5/C6 & 7.3 & 7.6 & 3.2 & -4.6 & 4.4 & 10.3 & -5.2 & -13.2 & 1.9 & 7.5 & -10.3 & -9.8 & 3.3 & 8.6 & -12.3 & -10.8 \\
\hline Discover03 & C5/C6 & 13.8 & 13.9 & -1.5 & 9.4 & 11.9 & 10.4 & 7.4 & 2.1 & 7.2 & 6.4 & -2.9 & -1.3 & 12.5 & 15.7 & -7 & -8.6 \\
\hline Discover04 & C5/C6 & 9.1 & 6.7 & -5.4 & -7.4 & 7.5 & 6.5 & -8.1 & -9.1 & 5.1 & 7 & -2.5 & -7.6 & 3 & 7.7 & -16.1 & -11.2 \\
\hline Discover05 & $\mathrm{C} 6 / \mathrm{C7}$ & 9.5 & 8.5 & -0.7 & -7.1 & 8.5 & 15.2 & -5.5 & -11 & 7.9 & 9 & -8.8 & -11.5 & 7.5 & 15.6 & -7.3 & -21.7 \\
\hline Discover06 & C5/C6 & 13.7 & 15.5 & -1.5 & -35.7 & 4.8 & 8.4 & -5.9 & -7.6 & 7.3 & 8.1 & -5.4 & -6.1 & 8.8 & 7.6 & -5.1 & -6.6 \\
\hline Discover07 & C5/C6 & 7.6 & 7.4 & -7.1 & -20.8 & 9.7 & 12 & -10.1 & -6.8 & 9.2 & 27.8 & -5 & -12.9 & 3.1 & 10.9 & -10.4 & -7.9 \\
\hline Discover08 & C4/C5 & 3.7 & 11.2 & -3 & 3.6 & 6.6 & 7.6 & -5.3 & -3.9 & 4 & 8.3 & -8.1 & -9.6 & 3 & 10.8 & -14.1 & -10.6 \\
\hline Discover09 & C5/C6 & & & & & 8.5 & 6.3 & -6.5 & -5.8 & 17.6 & 6.1 & 17.8 & -6.8 & 6.5 & 8.7 & -16.4 & -6.3 \\
\hline Discover10 & $\mathrm{C} 6 / \mathrm{C} 7$ & 3.2 & & -0.7 & & 9.3 & 15 & -1.1 & -8.5 & 7.5 & 2.3 & -5.2 & -6.5 & 2.2 & 5.9 & -4.9 & -5.8 \\
\hline Prestige01 & C6/C7 & 13.4 & -2.1 & -14.1 & -7.9 & 8.5 & 8.1 & -5 & -4.7 & 9.9 & 6.4 & -8 & -5.1 & 12.2 & 5.5 & -7.6 & -10.4 \\
\hline Prestige02 & $\mathrm{C} 6 / \mathrm{C} 7$ & 8.5 & 4.8 & -3.8 & -5.1 & 7.2 & 8.2 & -8.5 & -8.6 & 13 & 9.7 & -2.7 & -8.1 & 8.3 & 8.5 & -5.9 & -6.9 \\
\hline Prestige03 & C5/C6 & & & & & 5.3 & & -10.5 & & 9.3 & & -6.9 & & 12.8 & & -12.3 & \\
\hline Prestige04 & C6/C7 & 6.5 & 6.6 & -0.3 & -2.1 & 20.2 & 11.8 & 6.4 & -2.9 & 8 & 5.3 & -7.9 & -8.9 & 4 & 6.7 & -9 & -5.3 \\
\hline Prestige05 & $\mathrm{C} 5 / \mathrm{C} 6$ & 7.1 & & 0.5 & & 6.1 & 8.3 & -2.3 & 6.6 & 4.2 & 9.3 & -8.4 & -8.6 & 5 & 14.7 & -12.3 & -8.8 \\
\hline Prestige06 & C5/C6 & 4.9 & -2 & -32.8 & -37.7 & 7.5 & 0.2 & -8.5 & -9.6 & 10.1 & 6 & -10 & -12.7 & 8.7 & 1.7 & -8.3 & -11.9 \\
\hline Prestige07 & C5/C6 & -2.7 & 10.8 & -1.9 & -7 & 6 & 6.8 & -7.9 & -8.1 & 2.9 & 1.1 & -5.5 & -5.6 & 4.8 & -0.2 & -8.9 & -13.6 \\
\hline Prestige08 & C5/C6 & 2.8 & 9 & -1.3 & 6.5 & 7.7 & 6.6 & -5.4 & -4.3 & 2.6 & 2.5 & -4.9 & -8.7 & 4.7 & 1.8 & -11.6 & -5.8 \\
\hline Prestige09 & $\mathrm{C} 5 / \mathrm{C} 6$ & 8.7 & 7 & -1.3 & 0 & 6.2 & 5.5 & -4.6 & 1.9 & 7.5 & 1.5 & -3.5 & -3.5 & 4.8 & 1.2 & -3.4 & -8 \\
\hline Prestige10 & C6/C7 & 19.7 & 27.6 & -7.4 & 30.2 & 1.6 & 2.2 & -5.2 & 0.3 & 4.4 & 8.5 & -5 & -7.7 & 10.6 & 5.5 & -6.9 & -14.1 \\
\hline Mean & & 7.9 & 7.7 & -5.1 & -4.1 & 6.9 & 8.3 & -5.9 & -5.2 & 6.9 & 7.1 & -5.7 & -7.6 & 7.8 & 7.5 & -8.6 & -8.3 \\
\hline Median & & 7.5 & 7.4 & -2.0 & -2.1 & 7.2 & 8.2 & -5.7 & -6.2 & 7.3 & 7.4 & -6.6 & -7.8 & 7.6 & 7.3 & -8.0 & -9.3 \\
\hline SD & & 4.5 & 7.0 & 9.2 & 13.2 & 4.4 & 3.6 & 4.7 & 5.3 & 3.6 & 4.8 & 6.2 & 3.2 & 4.9 & 4.1 & 5.6 & 7.4 \\
\hline$p$ value & & 0.928 & & 0.757 & & 0.187 & & 0.604 & & 0.844 & & 0.130 & & 0.820 & & 0.888 & \\
\hline
\end{tabular}

$x$ - and $y$-coordinates in millimeters 


\section{Results}

Data for C6/7 was spared from the datasets Bryan08post-op; Discover09 pre- and post-op; Discover10 preop; Prestige05 pre-op because the necessary landmarks for biomechanical calculation could not be determined as C7 was covered from the patients' shoulders. Also data was spared from analysis from the datasets Bryan05-C5/6 pre-op; Bryan08-C5/6 post-op because segmental ROM was below $2^{\circ}$ and therefore reliable calculation of the COR was not possible. The post-op Prestige03-dataset was not suitable for COR analysis and was therefore completely excluded from further analysis.

\section{ROM healthy volunteers}

Fifteen datasets were analyzed; the mean ROM for flexion/extension from C3 to C7 was 53.4 (SD 12.7). Table 1 shows the mean values for maximum flexion/extension of the respective motion segments

\section{ROM patients}

Twenty-six datasets could be analyzed for pre- and postoperative ROM from C3 to C7; 10 from the Bryan subgroup, 8 from the Discover subgroup, and 8 from the Prestige subgroup. The mean ROM for flexion/extension from C3 to $\mathrm{C} 7$ was pre-operatively $38.3^{\circ}$ (SD 11.7) and post-operatively $43.4^{\circ}$ (SD 8.9). The mean ROM of the respective segments both for all patients and for the 3 subgroups are shown in Table 1.

\section{COR for maximum flexion/extension healthy volunteers}

The following coordinates (mean, SD) were found for flexion/extension: C3/4: $x 4.8 / y-5.8$ (2. /5.6); C4/5: $x 4.8 / y$ 3.8 (2.3/3.7); C5/6: x4.8/y-4.0 (2.8/3.1); C6/7: $x 4.9 / y-1.1$ (3.2/2.6) (Fig. 3).

\section{COR for maximum flexion/extension all patients}

Table 2 shows the $x$ - and $y$-coordinates of the COR from all patients and levels. Table 3 compares the pre- and post-operative COR-coordinates (mean values) from all patients-irrespective of the prosthesis type and the operated level-with the COR-HV. It shows that the preoperative $x$-coordinates of the patients differ considerably in all levels from the COR-HV, and that the preoperative COR for flexion/extension is located more anteriorly than in healthy subjects. Post-operatively, the COR for $\mathrm{C} 3 / 4$ remains nearly unchanged. The CORs for $\mathrm{C} 4 / 5$ and $\mathrm{C} 5 / 6$ shift away from the normal COR-HV (C4/5 inferiorly, C5/6 anteriorly). For the COR C6/7, the $x$-coordinates remain nearly unchanged and the $y$-coordinates mildly shift toward the normal COR-HV (Fig. 4).

\section{Bryan subgroup}

Table 4 summarizes the pre- and post-operative CORcoordinates (mean values) from the Bryan-subgroup
Table 3 COR mean values pre- and post-op: all patients -irrespective of implanted prosthesis - compared with $\mathrm{COR}$ in healthy volunteers (COR-HV)

\begin{tabular}{|c|c|c|c|c|c|c|c|}
\hline \multicolumn{2}{|c|}{ Segment } & \multicolumn{2}{|c|}{ COR-HV } & \multicolumn{2}{|c|}{ COR pre-op } & \multicolumn{2}{|c|}{ COR post-op } \\
\hline & & $x$ & $y$ & $x$ & $y$ & $x$ & $y$ \\
\hline \multirow[t]{3}{*}{$\mathrm{C} 6 / 7$} & Mean & 4.9 & -1.1 & 7.9 & -5.1 & 7.7 & -4.1 \\
\hline & SD & 3.2 & 2.6 & 4.5 & 9.2 & 7.0 & 13.2 \\
\hline & $p$ & & & 0.029 & 0.115 & 0.146 & 0.397 \\
\hline \multirow[t]{3}{*}{ C5/6 } & Mean & 4.8 & -4.0 & 6.9 & -5.9 & 8.3 & -5.2 \\
\hline & SD & 2.8 & 3.1 & 4.4 & 4.7 & 3.6 & 5.3 \\
\hline & $p$ & & & 0.097 & 0.179 & 0.002 & 0.443 \\
\hline \multirow[t]{3}{*}{$C 4 / 5$} & Mean & 4.8 & -3.8 & 6.9 & -5.7 & 7.1 & -7.6 \\
\hline & SD & 2.3 & 3.7 & 3.6 & 6.2 & 4.8 & 3.2 \\
\hline & $p$ & & & 0.055 & 0.305 & 0.099 & 0.001 \\
\hline \multirow[t]{3}{*}{$C 3 / 4$} & Mean & 4.8 & -5.8 & 7.8 & -8.6 & 7.5 & -8.3 \\
\hline & SD & 2.3 & 5.6 & 4.9 & 5.6 & 4.1 & 7.4 \\
\hline & $p$ & & & 0.035 & 0.123 & 0.026 & 0.248 \\
\hline
\end{tabular}

compared with the COR-HV; the COR for $\mathrm{C} 3 / 4$ is shifted toward the normal COR-HV. The COR for C4/5 nearly remains unchanged. For $\mathrm{C} 5 / 6$, the $x$-coordinates of the COR are shifted away from normal and the $y$-coordinates are shifted toward the normal COR-HV. For $\mathrm{C} 6 / 7$ the COR is shifted toward the normal COR-HV (Fig. 5).

\section{Discover subgroup}

Table 5 summarizes the pre- and post-operative CORcoordinates (mean values) from the Discover-subgroup compared with the COR-HV; in C3/4, the $x$-coordinates of the COR are considerably shifted away from normal, and the $y$-coordinates are mildly toward the normal COR-HV. However, in C4/5, C5/6, and C6/7, the COR is considerably shifted away from the normal COR-HV both for the $x$-and the $y$-coordinates (Fig. 6).

\section{Prestige subgroup}

Table 6 summarizes the pre- and post-operative CORcoordinates (mean values) from the Prestige subgroup compared with the COR-HV; for the CORs for C3/4 and $\mathrm{C} 4 / 5$, the $x$-coordinates are shifted near to normal, but the $y$-coordinates are shifted considerably away from the normal COR-HV. In C5/6, the $x$-coordinates are shifted mildly toward normal and the $y$-coordinates switch from negative to positive values with a mild improvement toward the normal COR-HV. In C6/7, the $x$-coordinates remain nearly unchanged, and the $y$-coordinates are shifted toward the normal COR-HV (Fig. 7).

These findings claim the following results: 


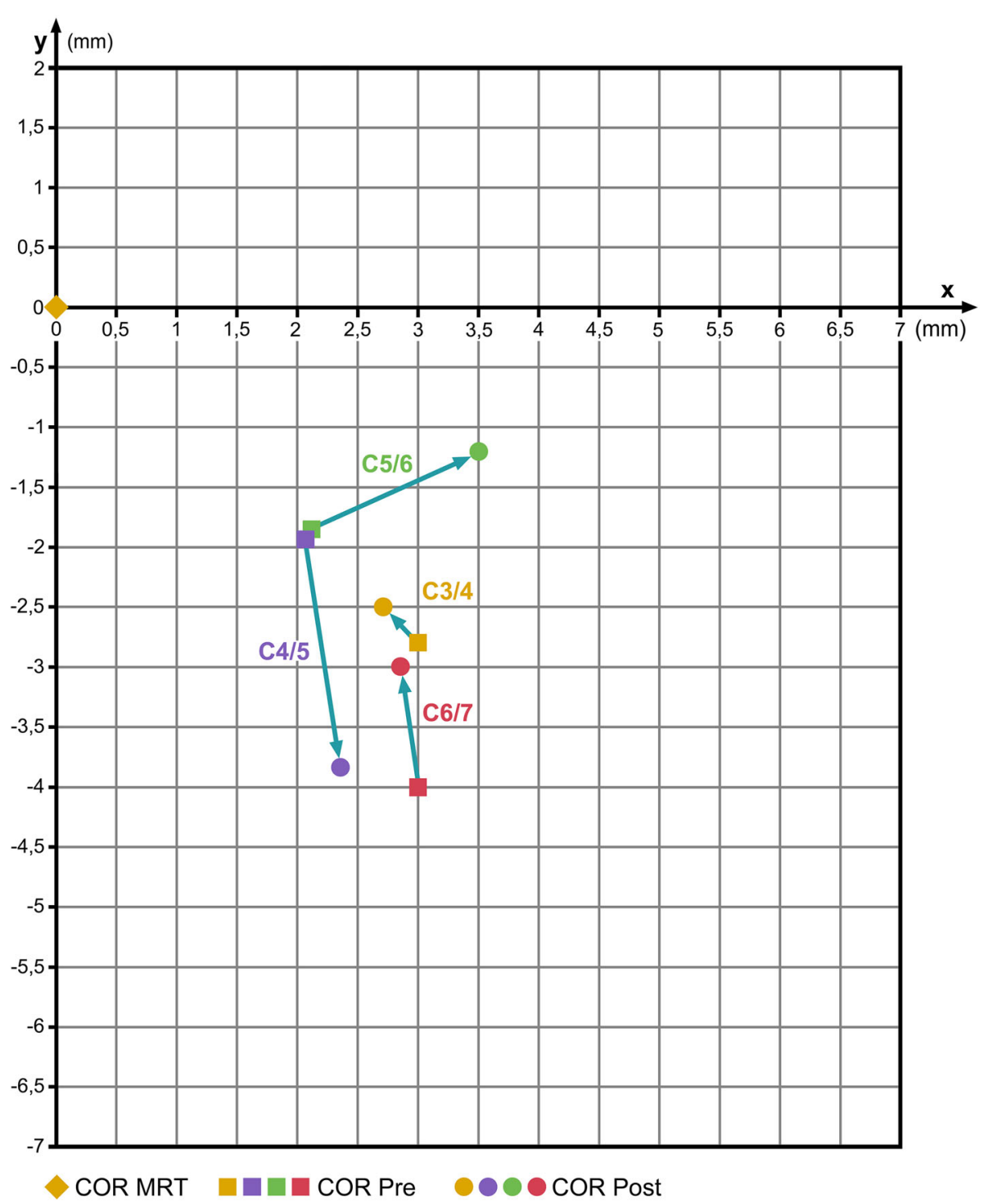

Fig. 4 Change of COR after insertion of a disc prosthesis irrespective of the prosthesis type. Coordinate origin 0/0 represents the respective COR in healthy volunteers

1. The pre-operative COR is not congruent with the COR found in healthy subjects; once a disc herniations occurs, the motion pattern changes, and the pre-op COR should not be used as reference anymore.

2. The post-op position of the COR considerably varies depending on the biomechanical concept of the prosthesis: devices with a ball socket design (fixed COR) can shift the COR considerably away from the physiological COR; prostheses with inverse ball socket design and potential for longitudinal translation can shift the $x$-coordinates moderately toward normal, but the $y$-coordinates can be shifted considerably off from the COR-HV; prostheses with variable COR can considerably improve the position of the COR toward normal at least in certain motion segments.

3. The post-op shift of the COR was noted in all investigated levels irrespective of the operated level. This demonstrates that biomechanical changes in one motion segment can cause a cascade of compensatory effects in all other levels.

4. As long as it is not scientifically proven that prosthesis design has no impact on clinical outcome, surgeons should choose devices with a more sophisticated biomechanical concept considering that the COR varies between segments and also changes its position during motion. 


\section{Discussion}

A great variety of biomechanical studies have been published about cervical arthroplasty. Most studies focus on the ROM or on changes in disc height and facet translation compared with normal individuals and with patients after ACDF or on clinical results [10-22]. Several studies also investigate qualitative motion of disc prostheses [19], but we did not find studies investigating how the COR after insertion of a prosthesis compares with healthy individuals, which is important because our data shows that the COR in patients with disc herniations is not at a physiological position anymore and therefore the pre-op COR cannot be used as reference:

Anderson et al. undertook a meta-analysis on kinematics of the cervical adjacent segments after disc arthroplasty compared with anterior discectomy and fusion [10]. Twelve papers were identified to meet the inclusion criteria, but only 2 of them-Park et al. [5] and Powell et al. [7]-investigated COR. The Powell study compared COR after 22 Bryan prostheses with 26 patients after ACDF. At the index level, the COR shifted more posterior $(0.3 \mathrm{~mm})$ and cephalad (4.9 $\mathrm{mm}$ ) post-operatively. At the adjacent level above, COR was significantly posterior compared with fusion. There was no significant difference at the level below fusion. The study published by Park et al. investigated 272 patients after arthroplasty with a PCM cervical artificial disc; at the index-level, COR-x was found 0.8 $\mathrm{mm}$ posterior to the disc center before surgery and $0.2 \mathrm{~mm}$ anterior to the center at 12 months after TDR. COR-y was $2.5 \mathrm{~mm}$ below the endplate before and $4.0 \mathrm{~mm}$ at 12 months after surgery. COR at the adjacent levels was unaltered in this study by fusion or arthroplasty. Comparing these 2 studies reveals that different biomechanical prostheses concepts also influence the post-op position of the COR differently; however, other than in our study, none of these 2 studies provides data whether the change of the COR represents an improvement toward physiological values at the respective levels or rather a further shift out of the physiological range of a normal COR.

Liu et al. presented an in vivo study investigating the inter-segmental ROMs and introducing a mathematical model calculating contact forces of normal, fused, and post-arthroplasty cervical spines; they concluded that arthroplasty can preserve motion and force patterns of the normal cervical spine, but no data are presented on COR [4].

Pickett et al. investigated the COR in 20 patients after receiving a Bryan artificial disc [6]. It was found that the COR did not change significantly at the index level or any other level after surgery. They state that the Bryan device is able to provide a clinically adequate range of COR; but no comparison with normal values is presented. In our study, the COR after inserting a Bryan prosthesis was found more close to the COR-HV than with the other devices.

Rousseau et al. compared the kinematics of the Prestige LP prosthesis with the ProDsic-C prosthesis in an in vivo study [8]. The COR for the Prestige LP was found above the disc level and the COR for the ProDisc $\mathrm{C}$ below it. Only average values for both CORs are presented. They conclude that arthroplasty devices using a ball socket design influence inter-vertebral kinematics for flexion/extension. We found similar biomechanical properties for the Prestige LP and the Discover (which is in its biomechanical design very similar to the ProDisc $\mathrm{C})$, and we believe this reflects typical motion patterns for devices with the COR above disc level (Prestige) or below disc level (Discover, ProDisc C).

Koller et al. investigated biomechanical changes after insertion of a Discover prosthesis in 19 patients [1]. They found that COR-x shifted anteriorly outside of normal limits in approximately $50 \%$ of their patients. The shell angle and the position of the prostheses significantly correlated with the position of the COR-x and the COR-y. However, other than in our study, their COR data were pooled and overlaid on the C5/6 level. Still, their findings compare well with our data from the Discover patients showing worsening of the post-op COR due to the fixed ball socket design.

Kowalczyk et al. presented an in vivo kinematic study comparing the Bryan-, ProDisc $\mathrm{C}$, and the Prestige LP prostheses and their impact on the sagittal balance and segmental kinematics of the cervical spine [2]. In their study, the Bryan disc did not change the COR-x or COR-y significantly; in the ProDisc-C group, the COR-x

Table 4 COR mean values pre- and post-op after implantation of a Bryan prosthesis compared with COR in healthy volunteers (COR-HV)

\begin{tabular}{|c|c|c|c|c|c|c|c|}
\hline \multicolumn{2}{|c|}{ Segment } & \multicolumn{2}{|c|}{ COR-HV } & \multicolumn{2}{|c|}{ COR pre-op } & \multicolumn{2}{|c|}{ COR post-op } \\
\hline & & $x$ & $y$ & $x$ & $y$ & $x$ & $y$ \\
\hline \multirow[t]{3}{*}{ C6/7 } & Mean & 4.9 & -1.1 & 7.7 & -6.3 & 5.7 & -1.7 \\
\hline & SD & 3.2 & 2.6 & 3.6 & 11.4 & 7.2 & 4.2 \\
\hline & $p$ & & & 0.049 & 0.101 & 0.684 & 0.676 \\
\hline \multirow[t]{3}{*}{ C5/6 } & Mean & 4.8 & -4.0 & 5.1 & -8.1 & 8.5 & -5.6 \\
\hline & SD & 2.8 & 3.1 & 5.5 & 4.4 & 3.6 & 6.0 \\
\hline & $p$ & & & 0.832 & 0.014 & 0.010 & 0.389 \\
\hline \multirow[t]{3}{*}{$C 4 / 5$} & Mean & 4.8 & -3.8 & 6.3 & -6.8 & 6.5 & -7.9 \\
\hline & SD & 2.3 & 3.7 & 3.1 & 7.1 & 3.1 & 3.2 \\
\hline & $p$ & & & 0.173 & 0.182 & 0.139 & 0.010 \\
\hline \multirow[t]{3}{*}{$C 3 / 4$} & Mean & 4.8 & -5.8 & 9.9 & -7.3 & 7.4 & -7.0 \\
\hline & SD & 2.3 & 5.6 & 6.8 & 8.1 & 3.1 & 10.9 \\
\hline & $p$ & & & 0.012 & 0.587 & 0.028 & 0.720 \\
\hline
\end{tabular}


was shifted anteriorly, and in the Prestige LP group, the COR-y was shifted superiorly. This is similar to our findings for these 3 different biomechanical concepts; however, other than in our study, no data on how these findings compare to normal individuals are presented.

So, the findings from most of these studies support our claim that the biomechanical design of a prosthesis has an impact on the post-op motion pattern, and especially simple ball socket devices can make things even worse. Our study adds additional information how the post-op COR after inserting the different devices compares to healthy individuals. We believe this is important, because a disc prosthesis can only claim to resemble natural motion when the post-op motion pattern of the operated segment compares well to healthy subjects rather than to the motion pattern of a segment affected by a damaged disc.

Regarding clinical outcome, the literature does not support the wide-spread opinion that prosthesis-design does not matter: Upadhyaya et al. [22] published an analysis of 3 randomized multicenter US FDA investigational device exemption cervical arthroplasty trials (Heller et al. [14]: Bryan; Mummaneni et al. [18]: Prestige; Murrey et al. [19]: ProDisc C). Similar to our study, the prostheses in these trials represent the same 3 different biomechanical concepts: variable COR (Bryan), COR for flexion/extension above the disc level with longitudinal translation (Prestige), and fixed COR below the disc level and ball socket design (ProDisc C), which is very similar to the design of the Discover prosthesis which was investigated in our

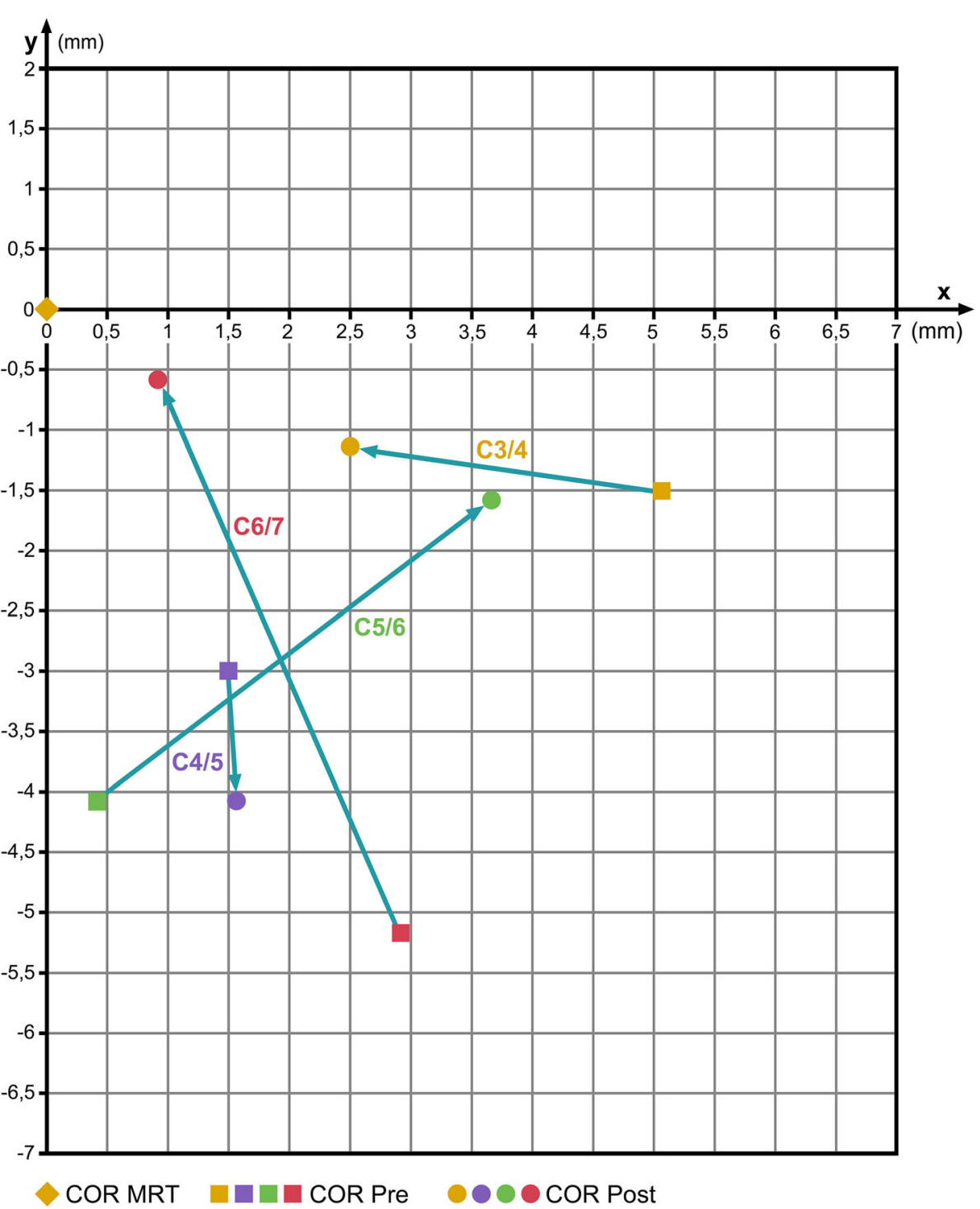

Fig. 5 Change of COR after insertion of a Bryan disc prosthesis. Coordinate-origin 0/0 represents the respective COR in healthy volunteers 
Table 5 COR mean values pre- and post-op after implantation of a Discover prosthesis compared with COR in healthy volunteers (COR-HV)

\begin{tabular}{|c|c|c|c|c|c|c|c|}
\hline \multirow[t]{2}{*}{ Segment } & & \multicolumn{2}{|c|}{ COR-HV } & \multicolumn{2}{|c|}{ COR pre-op } & \multicolumn{2}{|c|}{ COR post-op } \\
\hline & & $x$ & $y$ & $x$ & $y$ & $x$ & $y$ \\
\hline \multirow[t]{3}{*}{$66 / 7$} & Mean & 4.9 & -1.1 & 8.2 & -1.8 & 9.9 & -8.0 \\
\hline & SD & 3.2 & 2.6 & 3.8 & 3.0 & 3.3 & 14.3 \\
\hline & $p$ & & & 0.031 & 0.542 & 0.002 & 0.079 \\
\hline \multirow[t]{3}{*}{$C 5 / 6$} & Mean & 4.8 & -4.0 & 7.7 & -4.6 & 9.9 & -6.5 \\
\hline & SD & 2.8 & 3.1 & 2.3 & 4.8 & 3.3 & 4.6 \\
\hline & $p$ & & & 0.011 & 0.721 & 0.000 & 0.118 \\
\hline \multirow[t]{3}{*}{$C 4 / 5$} & Mean & 4.8 & -3.8 & 7.0 & -3.9 & 9.0 & -7.4 \\
\hline & SD & 2.3 & 3.7 & 4.4 & 8.0 & 6.9 & 3.8 \\
\hline & $p$ & & & 0.117 & 0.988 & 0.039 & 0.030 \\
\hline \multirow[t]{3}{*}{$C 3 / 4$} & Mean & 4.8 & -5.8 & 5.8 & -9.8 & 9.8 & -8.7 \\
\hline & SD & 2.3 & 5.6 & 3.4 & 4.7 & 3.5 & 6.1 \\
\hline & $p$ & & & 0.419 & 0.076 & 0.000 & 0.234 \\
\hline
\end{tabular}

study. The improvement for the NDI in these studies was best for the Bryan device, followed by Prestige and ProDisc C. The improvement for neck pain frequency and intensity was best for the Bryan, followed by Prestige and ProDisc C. Neurological success was best with the Prestige prosthesis, followed by Bryan and ProDisc C. These findings support our opinion that a more flexible biomechanical prosthesis design can contribute to better clinical results. The ranking for NDI improvement in this study exactly reflects our findings for improvement of post-op COR.

However, a randomized study directly comparing clinical outcome for these devices is still lacking, and the papers presenting the 10-year results for these 3 devices are hardly comparable: regarding VAS neck/arm, for instance, for the BRYAN prothesis improvement of $\Delta 54.3$ / $\Delta 58.1$ (75.4-20.9/71.2-14.1) is reported [23]; for PorDisc C $\Delta 45 / \Delta 42$ (64-19/63-21) [24], but the considerable pre-op VAS-difference between BRYAN and ProDisc C allows no valid conclusion; and for the Prestige LP, VAS improvement is given as a percentage $(60.7 \% / 59.6 \%)$ [25] and therefore is not comparable either. A multi-center study relating clinical outcome to the biomechanical concepts of the respective prostheses would be highly desirable.

Staudt published a review on a variety of first- and second-generation cervical disc prosthesis and concludes that knowledge of implant design and design-specific advantages and disadvantages will become increasingly important to guide surgeon decision-making [26]. We completely share the opinion in this review, and we hope that our study can also contribute to decision-making in clinical practice by showing that a flexible biomechanical prosthesis-design can lead to better post-op qualitative motion.
Skeppholm reported a higher re-operation rate following cervical arthroplasty compared to ACDF; in this study, 151 patients received a Discover disc (DePuy Spine) and 21 a Prestige LP disc (Medtronic) compared to 504 patients with ACDF. The most common reason for re-operation in the arthroplasty group was implant migration or instability. Unfortunately, no data is given whether re-operation rate could be related to implant design [27], probably because of the significantly different cohorts (151 Discover/21 Prestige prostheses), but the question how implant migration in this study compares to the biomechanical findings for the same devices in our study would be of high interest.

Ryu et al. [28] investigated radiological changes of the operated and adjacent segments following cervical arthroplasty after a minimum 24-month follow-up: 19 patients with Bryan prosthesis were compared with 17 patients with ProDisc $\mathrm{C}$ prosthesis: progression of radiological degeneration at the index level was seen in 1 Bryan patient and in 6 ProDisc $C$ patients. This is remarkable with respect to our findings, and the question arises whether the humble biomechanical concept of a fixed ball socket design not only influences qualitative motion to a worse pattern as is showed in our study, but also triggers further radiological degeneration.

Limitations of our study mainly arise from the small number of datasets, and therefore strong conclusions may not be drawn; we hope our findings will encourage others to initiate further studies with larger cohorts to define more precisely the biomechanical differences between healthy individuals and patients being candidates for cervical disc surgery.

Also, our patient data were collected retrospectively, but we believe this has little or no influence on determination of the COR.

Limitations also arise from the technique how the respective coordinates were determined: the interindividual differences in the size of the vertebral bodies were not reflected when giving the coordinates of the COR in millimeters and not as a percentage of the vertebral bodies' diameter. However, the error resulting from this limitation is expected below $1 \mathrm{~mm}$ and should not put our results into question.

Further, COR-HV was determined from MRI; there are techniques described in the literature that are more precise, like stereoradiography plus 3D-CT; however, this leads to radiation exposure of approx. 4MSV [29] which is a high burden for healthy volunteers. Also, differences in the motion pattern may occur whether the cervical spine is investigated in supine position in MRI compared to fluoroscopy where patients are in upright weight-bearing position with. But nevertheless, at least in Europe, one would hardly get permission from the Ethics Committee for a study design exposing healthy 


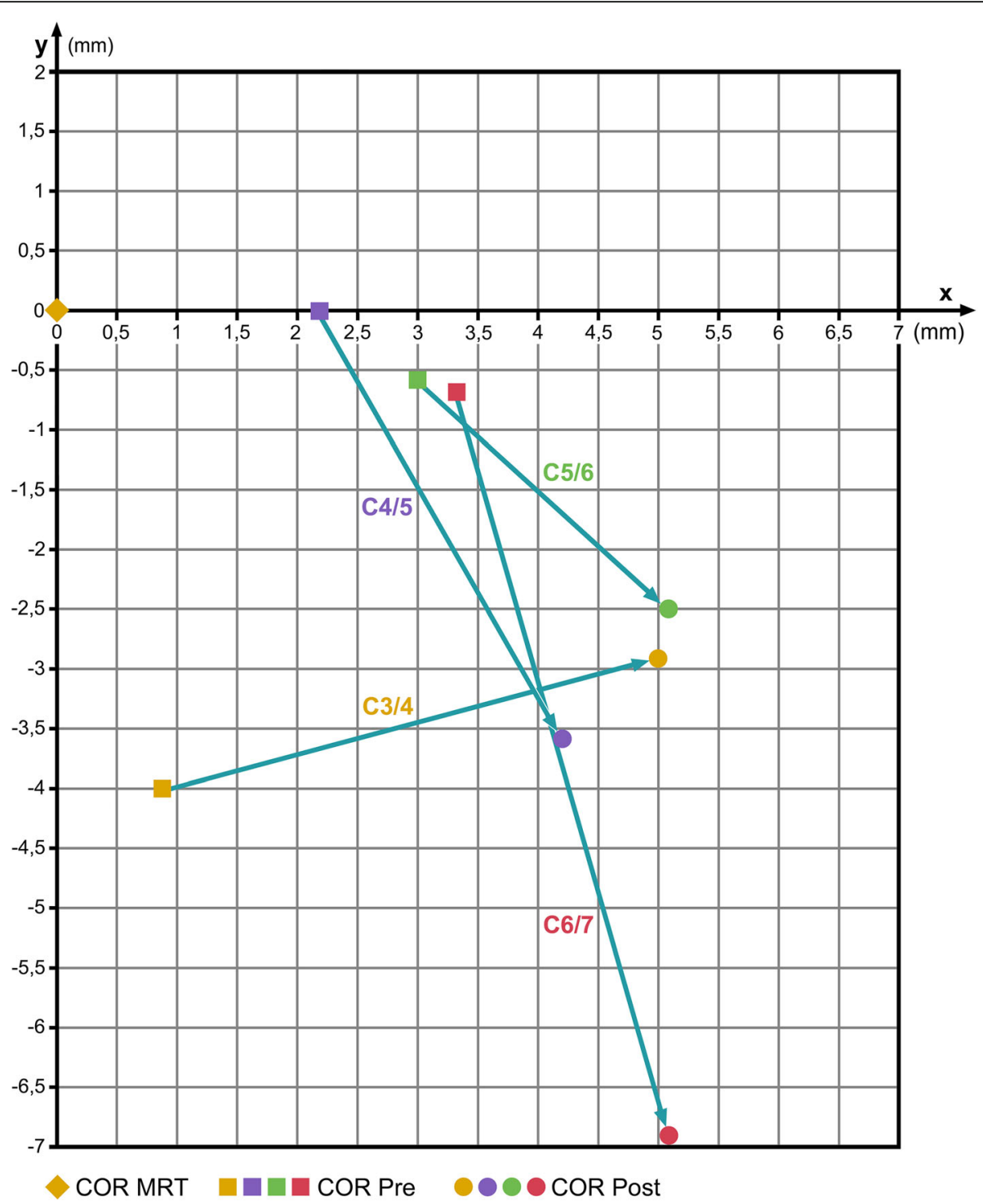

Fig. 6 Change of COR after insertion of a Discover disc prosthesis. Coordinate-origin 0/0 represents the respective COR in healthy volunteers

Table 6 COR mean values pre- and post-op after implantation of a Prestige prosthesis compared with COR in healthy volunteers (COR-HV)

\begin{tabular}{|c|c|c|c|c|c|c|c|}
\hline \multirow[t]{2}{*}{ Segment } & & \multicolumn{2}{|c|}{ COR-HV } & \multicolumn{2}{|c|}{ COR pre-op } & \multicolumn{2}{|c|}{ COR post-op } \\
\hline & & $x$ & y & $x$ & $y$ & $x$ & $y$ \\
\hline \multirow[t]{3}{*}{ C6/7 } & Mean & 4.9 & -1.1 & 7.7 & -6.9 & 7.7 & -2.9 \\
\hline & SD & 3.2 & 2.6 & 6.3 & 10.7 & 9.3 & 18.7 \\
\hline & $p$ & & & 0.163 & 0.054 & 0.289 & 0.718 \\
\hline \multirow[t]{3}{*}{ C5/6 } & Mean & 4.8 & -4.0 & 7.6 & -5.2 & 6.4 & -3.3 \\
\hline & SD & 2.8 & 3.1 & 4.8 & 4.7 & 3.5 & 5.4 \\
\hline & $p$ & & & 0.072 & 0.479 & 0.216 & 0.660 \\
\hline \multirow[t]{3}{*}{$C 4 / 5$} & Mean & 4.8 & -3.8 & 7.2 & -4.7 & 5.6 & -7.7 \\
\hline & SD & 2.3 & 3.7 & 3.5 & 2.3 & 3.3 & 2.7 \\
\hline & $p$ & & & 0.052 & 0.078 & 0.511 & 0.014 \\
\hline \multirow[t]{3}{*}{$C 3 / 4$} & Mean & 4.8 & -5.8 & 7.6 & -4.5 & 5.0 & -9.4 \\
\hline & SD & 2.3 & 5.6 & 3.4 & 2.9 & 4.6 & 3.3 \\
\hline & p & & & 0.022 & 0.153 & 0.881 & 0.090 \\
\hline
\end{tabular}




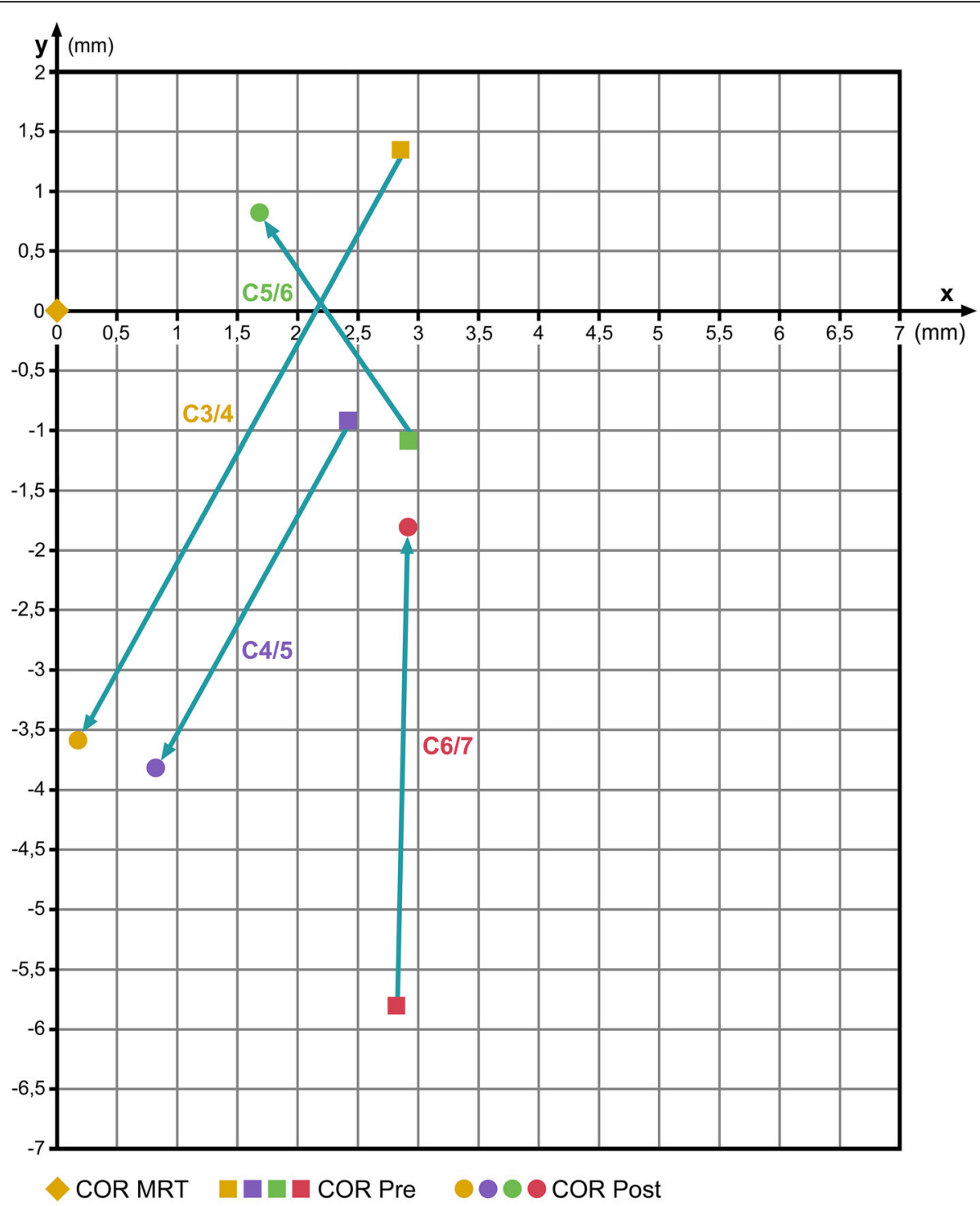

Fig. 7 Change of COR after insertion of a Prestige disc prosthesis. Coordinate-origin 0/0 represents the respective COR in healthy volunteers

volunteers to such a radiation dose. We are aware that for these reasons perfect consistency between the MRIand the fluoroscopic image coordinates cannot be achieved, but even taking into account such small error, we believe that the considerable differences we found for the COR-HV compared to the pre-op COR allow to claim that the COR in patients with disc herniations is not anymore where it is found in healthy subjects.

Even taking in account these limitations, we believe that our work shows how arthroplasty devices with different biomechanical concepts can influence postoperative cervical spine motion in a considerably different manner. Considering that flexion/extension is not a simple circular motion but has a variable COR even during motion, it must be concluded that disc prostheses with a simple ball socket design and fixed COR are not suitable to provide a physiological motion pattern for all cervical segments, and that devices with a more variable COR better contribute to re-establishing a more normal motion pattern. We hope that our study delivers useful new information for the daily practice of spine surgeons and will encourage anyone who is involved in cervical arthroplasty to look very closely on the biomechanical properties of the devices they chose.

\section{Conclusions}

Even if the small cohorts in our study do not allow strong conclusions, it seems that once a disc herniations occurs, the motion pattern changes, and the COR is not anymore where it is in healthy individuals. If so, the preop COR cannot be used as a reference when discussing whether a disc prosthesis is resembling natural motion. 
The biomechanical prosthesis-design considerably influences the post-op position of the COR: simple ball socket devices can shift the already abnormal COR to an even more unphysiological position; devices with a more flexible biomechanical design can contribute to normalize the coordinates of the COR.

An unphysiological post-op COR can cause a cascade of compensatory effects in all other levels.

Because there is no scientific evidence that prosthesis design does not influence clinical outcome, the biomechanical design should be taken into account when choosing an arthroplasty device, and only prostheses with flexible biomechanical properties should be used in clinical practice.

\section{Abbreviations}

ACDF: Anterior cervical discectomy and fusion; COR: Center of rotation; CORHV: Center of Rotation in Healthy Volunteers; NDI: Neck Disability Index; ROM: Range of motion

\section{Acknowledgements}

We highly acknowledge Dr. Karl Mahr, Dr. Karl-Heinz Pichler, Dr. Gabriele Wurm, and Dr. Helmut Hierz for their support in collecting and providing $\mathrm{X}$ rays for this study, and Ingrid Dobsak for her brilliant artistic work regarding the illustrations.

\section{Authors' contributions}

Author contributions to the study include the following: conception and design: M.M., E.T.; acquisition of data: all authors. Biomechanical calculations: E.T., W.S., H.S. Analysis and medical interpretation of data: M.M. and S.T.; drafting the article: M.M; critically revising the article: all authors. The authors read and approved the manuscript.

\section{Funding}

This paper was supported by the Anniversary Fund of the Oesterreischische National Bank (OeNB) project \# 12685. The sponsor had no role in the design or conduct of this research.

\section{Availability of data and materials}

The datasets used and/or analyzed during the current study (MRI pictures and X-rays used for biomechanical calculations) are available from the corresponding author on reasonable request.

\section{Ethics approval and consent to participate}

All procedures performed in studies involving human participants were in accordance with the ethical standards of the institutional and/or national research committee and with the 1964 Helsinki Declaration and its later amendments or comparable ethical standards. The study protocol was approved by the Ethic commission of the Medical University of Vienna (EK Nr. 571/2007).

\section{Consent for publication}

Not applicable

\section{Competing interests}

The authors declare that they have no competing interests.

\section{Author details}

'Neurosurgical Department, Donauspital SMZ-Ost, Langobardenstrasse 122 1220 Vienna, Austria. ${ }^{2}$ Vehicle Safety Institute, Graz University of Technology, Graz, Austria. ${ }^{3}$ High Field MR Center, Department of Biomedical Imaging and Image-guided Therapy, Medical University of Vienna, Vienna, Austria.
Received: 29 June 2020 Accepted: 20 August 2020

Published online: 09 September 2020

\section{References}

1. Koller H, Meier O, Zenner J, Mayer M, Hitzl W. In vivo analysis of cervical kinematics after implantation of a minimally constrained cervical artificial disc replacement. Eur Spine J. 2013:22:747-58.

2. Kowalczyk I, Lazaro BC, Fink M, Rabin D, Duggal N. Analysis of in vivo kinematics of 3 different cervical devices: Bryan disc, ProDisc-C, and Prestige LP disc. Clinical article. J Neurosurg Spine. 2011;15:630-5.

3. Lind B, Sihlbom $\mathrm{H}$, Nordwall A, Malchau H. Normal ranges of motion of the cervical spine. Arch Phys Med Rehabil. 1989;70:692-5.

4. Liu F, Cheng J, Komistek RD, Mahfouz MR, Sharma A. In vivo evaluation of dynamic characteristics of the normal, fused, and disc replacement cervical spines. Spine (Phila Pa 1976). 2007:32:2578-84.

5. Park DK, Lin EL, Phillips F. Index and adjacent level kinematics after cervical disc replacement and anterior fusion. Spine (Phila Pa 1976). 2011:36:721-30.

6. Pickett GE, Rouleau JP, Duggal N. Kinematic analysis of the cervical spine following implantation of an artificial cervical disc. Spine (Phila Pa 1976). 2005:30:1949-54

7. Powell JW, Sasso RC, Metcalf NH, Anderson PA, Hipp JA. Quality of spinal motion with cervical disk arthroplasty: computer-aided radiographic analysis. J Spinal Disord Tech. 2010;23:89-95

8. Rousseau MA, Cottin P, Levante S, Alexis N, Lazennec JY, Skalli W. In vivo kinematics of two types of ball-and-socket cervical disc replacements in the sagittal plane: cranial versus caudal geometric center. Spine (Phila Pa 1976). 2008;33:E6-9.

9. Bogduk N, Mercer S. Biomechanics of the cervical spine. I: Normal kinematics. Clin Biomech. 2000;15:633-48.

10. Anderson PA, Sasso RC, Hipp J, Norvell DC, Raich A, Hashimoto R. Kinematics of the cervical adjacent segments after disc arthroplasty compared with anterior discectomy and fusion: a systematic review and meta-analysis. Spine (Phila Pa 1976). 2012;37(22 Suppl):S85-95.

11. Davis RJ, Nunley PD, Kim KD, Hisey M, Jackson RJ, Bae HW, Hoffmann GA, Gaede SE, Danielson GO III, Gordon C, Stone MB. Two-level total disc replacement with Mobi-C cervical artificial disc versus anterior discectomy and fusion: a prospective, randomized, controlled multicenter clinical trial with 4-year follow-up results. J Neurosurg Spine. 2015;22:15-25.

12. Findlay C, Ayis S, Demetriades AK. Total disc replacement versus anterior cervical discectomy and fusion. Bone Joint J. 2018;100-B(8):991-1001.

13. Gao F, Mao T, Sun W, Guo W, Wang Y, Li Z, Abhinav P. An updated metaanalysis comparing artificial cervical disc arthroplasty (CDA) versus anterior cervical discectomy and fusion (ACDF) for the treatment of cervical degenerative disc disease. Spine (Phila Pa 1976). 2015;40:1816-23.

14. Heller JG, Sasso RC, Papadopoulos SM, Anderson PA, Fessler RG, Hacker RJ, Coric D, Cauthen JC, Riew DK. Comparison of BRYAN cervical disc arthroplasty with anterior cervical decompression and fusion: clinical and radiographic results of a randomized, controlled, clinical trial. Spine (Phila Pa 1976). 2009;34:101-7.

15. Kelly MP, Mok JM, Frisch RF, Tay BK. Adjacent segment motion after anterior cervical discectomy and fusion versus Prodisc-C cervical total disc arthroplasty: analysis from a randomized, controlled trial. Spine (Phila Pa 1976). 2011;36:1171-9.

16. Kim SW, Limson MA, Kim SB, Arbatin JJ, Chang KY, Park MS, et al. Comparison of radiographic changes after ACDF versus Bryan disc arthroplasty in single and bi-level cases. Eur Spine J. 2009:18:218-31.

17. McDonald CP, Chang V, McDonald M, Ramo N, Bey MJ, Bartol S. Threedimensional motion analysis of the cervical spine for comparison of anterior cervical decompression and fusion versus artificial disc replacement in 17 patients. J Neueosurg Spine. 2014;20:245-55.

18. Mummaneni PV, Burkus JK, Haid RW, Traynelis VC, Zdeblick TA. Clinical and radiographic analysis of cervical disc arthroplasty compared with allograft fusion: a randomized controlled clinical trial. J Neurosurg Spine. 2007;6:198-209.

19. Murrey D, Janssen M, Delamarter R, Goldstein J, Zigler J, Tay B, Darden B. Results of the prospective, randomized, controlled multicenter Food and Drug Administration investigational device exemption study of the ProDisc-C total disc replacement versus anterior discectomy and fusion for the treatment of 1-level symptomatic cervical disc disease. Spine 2009;9:275-86. 
20. Pointillart V, Castelain JE, Coudert P, Cawley DT, Gille O, Vital JM. Outcomes of the Bryan cervical disc replacement: fifteen year follow-up. Int Orthop. 2018:42:851-7.

21. Sasso RC, Best NM, Metcalf NH, Anderson PA. Motion analysis of Bryan cervical disc arthroplasty versus anterior discectomy and fusion: results from a prospective, randomized, multicenter, clinical trial. J Spinal Disord Tech. 2008;21:393-9.

22. Upadhyaya CD, Wu JC, Trost G, Haid RW, Traynelis VC, Tay B, Coric D, Mummaneni PV. Analysis of the three United States Food and Drug Administration investigational device exemption cervical arthroplasty trials. J Neurosurg Spine. 2012;16:216-28.

23. Lavelle WF, Riew KD, Levi AD, Florman JE. Ten-years outcomes of cervical disc replacement with the BRYAN cervical disc: Results from a prospective, randomized, controlled clinical trial. Spine (Phila Pa 1976). 2019;44:601-8.

24. Mehren C, Heider F, Siepe CJ, Zillner B, Kothe R, Korge A, Mayer HM. Clinical and radiological outcome at 10 years of follow-up after total cervical disc replacement. Eur Spine J. 2017;26:2441-9.

25. Gornet MF, Burkus JK, Shaffrey ME, Schranck FW, Copay AG. Cervical disc arthroplasty: 10-years outcomes of the Prestige LP cervical disc at a single level. J Neurosurg Spine. 2019;31:317-25.

26. Staudt MD, Das K, Duggal N. Does design matter? Cervical disc replacements under review. Neurosurg Rev. 2018;41:399-407.

27. Skeppholm M, Henriques T, Tullberg T. Higher reoperation rate following cervical disc replacement in a retrospective, long-term comparative study of 715 patients. Eur Spine J. 2017;26:2434-40.

28. Ryu KS, Park CK, Jun SC, Huh HY. Radiological changes of the operated and adjacent segments following cervical arthroplasty after a minimum 24month follow-up: comparison between the Bryan and Prodisc-C devices. J Neurosurg Spine. 2010;13:299-307.

29. Baillargeon $\mathrm{E}$, Anderst W. Sensitivity, reliability and accuracy of the instant center of rotation calculation in the cervical spine during in vivo dynamic flexion-extension. J Biomech. 2013;46:670-6.

\section{Publisher's Note}

Springer Nature remains neutral with regard to jurisdictional claims in published maps and institutional affiliations.

Ready to submit your research? Choose BMC and benefit from:

- fast, convenient online submission

- thorough peer review by experienced researchers in your field

- rapid publication on acceptance

- support for research data, including large and complex data types

- gold Open Access which fosters wider collaboration and increased citations

- maximum visibility for your research: over $100 \mathrm{M}$ website views per year

At $\mathrm{BMC}$, research is always in progress.

Learn more biomedcentral.com/submissions 